\title{
Dependence of TIMP-1 Plasma Levels on Preanalytical Specimen Handling
}

\author{
Marie Dresse $^{\mathrm{a}}$ Dorothea Nagel ${ }^{\mathrm{a}}$ Eva-Maria Ganser $^{\mathrm{a}}$ Gerard Davis $^{\mathrm{b}}$ \\ Barry Dowell $^{\mathrm{b}}$ Robert Doss $^{\mathrm{b}}$ Petra Stieber $^{\mathrm{a}}$ \\ anstitute of Clinical Chemistry, Klinikum Grosshadern, University of Munich, Munich, Germany; \\ ${ }^{b}$ Abbott Diagnostic Division, Chicago, III., USA
}

\section{Key Words}

Tissue inhibitor of metalloproteinases-1 - Handling •

Storage $\cdot$ Preanalytical $\cdot$ Freezing/thawing $\cdot$ Stability

\begin{abstract}
Background:Tissue inhibitor of metalloproteinases-1 (TIMP1) in blood might be a helpful biomarker in various diseases. However, various authors report that TIMP-1 is dependent on preanalytical procedures. Our study was performed to determine how storage conditions and time to centrifugation influence TIMP-1. Materials and Methods: Twenty-six blood specimens were collected from each of 20 volunteers. Two specimens from each person were centrifuged $/ \mathrm{mea}$ sured within $1 \mathrm{~h}$ after venipuncture and frozen at $-80^{\circ} \mathrm{C}$. They were thawed once or twice within $72 \mathrm{~h}$. Eight specimens were stored at $20^{\circ} \mathrm{C}$ in daylight, 8 at $20^{\circ} \mathrm{C}$ covered and 8 at $4^{\circ} \mathrm{C}$ in daylight. Four of each of these 8 specimens were mixed once a day until centrifugation. A mixed and an unmixed specimen of each group was centrifuged/measured after 3, 6, 24 and 72 h. Results: TIMP-1 increased after freeze/ thaw $(p<0.001)$. Mixing blood specimens more than once caused increased TIMP-1 $(p<0.001)$. TIMP-1 increased within $3 \mathrm{~h}$ of storage $(\mathrm{p}<0.001)$. The increase was lower in specimens covered and refrigerated $(p<0.001)$. Conclusion: TIMP-1 is unstable and has to be evaluated carefully. Blood should be centrifuged directly after venipuncture. For routine application, specimen handling must be standardized and carefully followed. Research should be done on specimens handled identically.

Copyright $\odot 2008$ S. Karger AG, Basel
\end{abstract}

\section{Introduction}

Tissue inhibitor of metalloproteinases-1 (TIMP-1) is a $28-\mathrm{kDa}$ glycoprotein which can be measured in peripheral blood by immunoassay [1]. The clinical use of TIMP1 in various diseases is currently being investigated and has been discussed by several groups. Several studies indicate that TIMP-1 may have clinical utility as tumor marker, since elevated levels occur in many patients suffering from colorectal cancer compared to healthy individuals [2-4]. Elevated TIMP-1 levels in colorectal cancer patients correlate with poorer prognosis and response to chemotherapy $[5,6]$. Elevated TIMP-1 levels have also been shown to predict worse outcome in breast cancer patients [7]. Furthermore, TIMP-1 plasma levels seem to play an important role in metabolic disorders, such as diabetes and adiposity [8-10], as well as in patients with cardiac disease [11-15] and sepsis [16]. In addition to these promising investigations, some authors have presented results indicating that TIMP-1 levels differ depending on pre- and perianalytical conditions [17-22]. Higher levels of TIMP-1 have been measured in serum than in plasma, which raised suspicion that TIMP-1 is released by leukocytes and platelets during the coagulation process and therefore plasma has been suggested to be the appropriate medium to measure TIMP-1 levels in peripheral blood [17, 19-21]. But even in plasma, changes in TIMP-1 levels under different specimen handling conditions have been observed [19, 21,22]. During our own investigations of TIMP-1 as a possible tumor marker, we

\section{KARGER}

Fax +4161306 1234 E-Mail karger@karger.ch www.karger.com
(C) 2008 S. Karger AG, Basel

1010-4283/08/0291-0035\$24.50/0

Accessible online at:

www.karger.com/tbi
Petra Stieber, MD

Institute of Clinical Chemistry, Klinikum Grosshadern, University of Munich

Marchioninistrasse 15, DE-81377 Muenchen (Germany)

Tel. +49 897095 3115, Fax +49 8970956298

E-Mail Petra.Stieber@med.uni-muenchen.de 




Fig. 1. Illustration of the experimental setup as described in $\mathrm{Ma}-$ terials and Methods.

measured higher TIMP-1 levels in the plasma specimens of healthy persons than in those of patients suffering from colorectal cancer, which may have been caused by the fact that the plasma specimens of the 2 groups had not been handled identically prior to their measurement. However, our results could not be explained by the existing studies on this topic. The present study was performed to verify our own observations and to understand how TIMP-1 levels in plasma are influenced by the preanalytical conditions of blood specimens that they would likely to be exposed to in daily routine, such as time to centrifugation, exposure to light, mechanical manipulation and freezing/thawing.

\section{Materials and Methods}

\section{Sampling}

Blood was collected from the antecubital vein of 20 healthy volunteers using a tourniquet. All specimens were simultaneously taken in plastic tubes of $2.3 \mathrm{ml}$ capacity containing EDTA (Monovette Systems; Sarstedt AG \& Co., Nümbrecht, Germany).

\section{Experimental Setup}

The pattern of the trial is shown in figure 1. From each of the 20 participants, 26 blood specimens were extracted into individual tubes. Two of each of the 26 specimens were processed into plasma and TIMP-1 was measured within $1 \mathrm{~h}$ after venipuncture. The remaining plasmas were kept frozen at $-80^{\circ} \mathrm{C}$. One of the 2 specimens from each person was then thawed and measured again after $24 \mathrm{~h}$ and refrozen, before both were thawed and measured after $72 \mathrm{~h}$. The other 24 blood specimens from each person were stored under different conditions prior to their centrifuga- tion and measurement: 8 were kept at $20^{\circ} \mathrm{C}$ and exposed to daylight, 8 were kept at $20^{\circ} \mathrm{C}$ but covered with aluminum foil and 8 were stored at $4^{\circ} \mathrm{C}$ in the cold storage room, where they were also exposed to light. The impact of mechanical manipulation on the blood specimens was tested by mixing 4 of each of these 8 specimens from all 3 storage conditions on a turntable for 30 min per day until centrifugation. A mixed and an unmixed specimen of each group was then centrifuged and measured after 3, 6, 24 and $72 \mathrm{~h}$.

\section{Laboratory Methods}

All specimens were centrifuged at $2,000 \mathrm{~g}$ at $4^{\circ} \mathrm{C}$ for $10 \mathrm{~min}$. The supernatant was transferred into dry plastic tubes. TIMP-1 was measured using an automated immunoassay (Architect System; Abbott Diagnostics, Abbott Park, Ill., USA). To test interassay variation, 2 specimens of each of 3 controls with low, intermediate and high TIMP-1 concentrations were simultaneously measured in each run. The mean (with SD in parentheses) and median (with range in parentheses) TIMP-1 values were $51.1 \mathrm{ng} /$ $\mathrm{ml}(1.2)$ and $51.29 \mathrm{ng} / \mathrm{ml}(48.4-53.1)$ for the low controls, 103.0 $\mathrm{ng} / \mathrm{ml}(2.4)$ and $102.7 \mathrm{ng} / \mathrm{ml}(98.8-108.4)$ for the medium controls and $312.5 \mathrm{ng} / \mathrm{ml}(9.9)$ and $312.5 \mathrm{ng} / \mathrm{ml}(294.2-333.2)$ for the high controls. The coefficients of variation resulting from these data are $2.4 \%, 2.3 \%$ and $3.2 \%$, respectively.

\section{Statistics}

All statistical calculations were done using SAS (version 9.1; SAS Institute, Cary, N.C., USA). For comparisons of TIMP-1 levels in corresponding plasma specimens, a t test was performed. Results were considered significant for $\mathrm{p}<0.05$.

\section{Results}

\section{Freezing/Thawing}

It was found that TIMP-1 levels increased after each freeze/thaw cycle. The measured TIMP-1 levels and the differences between the thawed specimens and those measured directly after centrifugation are shown in figure 2. Significantly higher TIMP-1 values were measured in specimen 1 after its second freeze/thaw cycle $72 \mathrm{~h}$ after venipuncture than after the first freeze/thaw cycle $24 \mathrm{~h}$ after venipuncture $(p<0.0001)$. In contrast, TIMP-1 values in specimen 2 measured after its first thawing $72 \mathrm{~h}$ after venipuncture were not higher than those in specimen 1 measured after its first thawing $24 \mathrm{~h}$ after venipuncture $(\mathrm{p}=0.71)$.

\section{Mechanical Manipulation}

While the applied mixing procedure did not influence TIMP-1 levels in the specimens centrifuged and measured after 3 and $6 \mathrm{~h}$, the mixed specimens stored 24 and $72 \mathrm{~h}$ prior to centrifugation showed significantly higher TIMP-1 levels than the corresponding unmixed specimens ( $\mathrm{p}<0.001)$. According to the experimental setup, 
Fig. 2. Influence of freeze/thaw on TIMP-1 levels in plasma: 2 of the 26 plasma specimens from each person were frozen and thawed once (labeled specimen 2) or twice (labeled specimen 1) within 72 h. Figures are means with SD in parentheses.

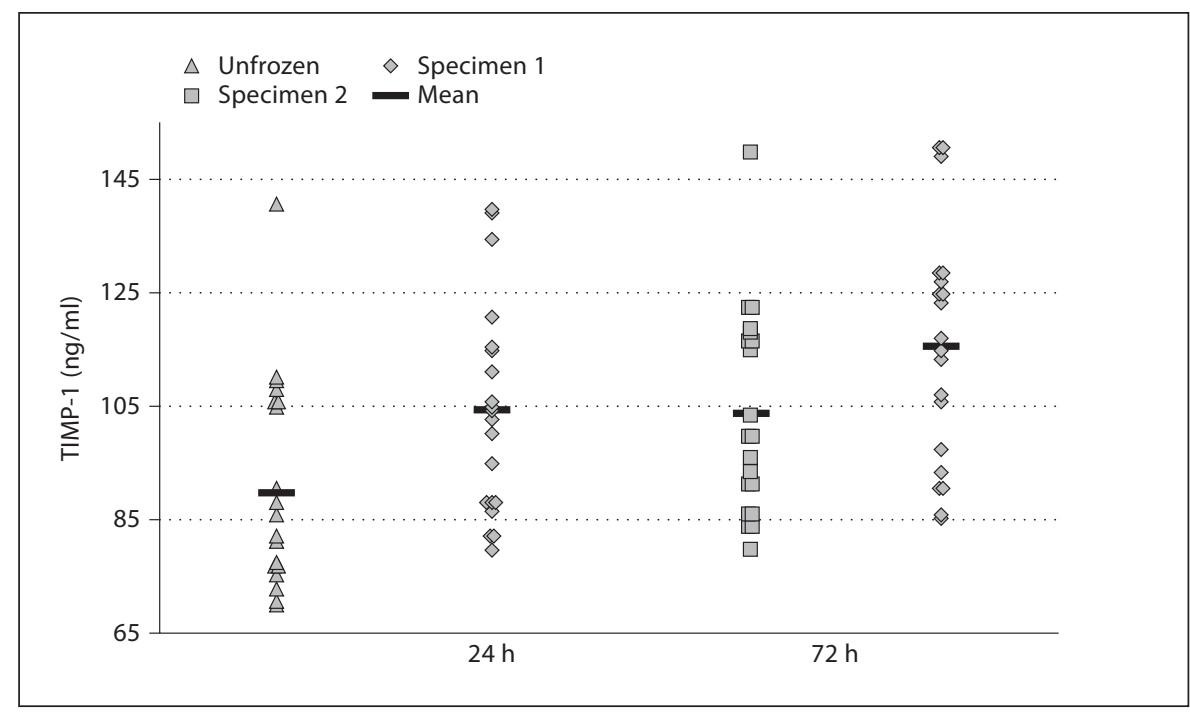

\begin{tabular}{|l|l|l|l|}
\hline Difference & $\begin{array}{l}\text { Specimen 1, } \\
\text { 1st thawing, 24 } \mathrm{h}\end{array}$ & $\begin{array}{l}\text { Specimen 2, } \\
\text { 1st thawing, 72 } \mathrm{h}\end{array}$ & $\begin{array}{l}\text { Specimen 1, } \\
\text { 2nd thawing, 72 } \mathrm{h}\end{array}$ \\
\hline Unfrozen & $\begin{array}{l}14.1(8.6) \\
\mathrm{p}<0.0001\end{array}$ & $\begin{array}{l}13.5(5.3) \\
\mathrm{p}<0.0001\end{array}$ & $\begin{array}{l}25.3(13.4) \\
\mathrm{p}<0.0001\end{array}$ \\
\hline $\begin{array}{l}\text { Specimen 1, } \\
\text { 1st thawing, 24 h }\end{array}$ & $\begin{array}{l}0.6(7.2) \\
\mathrm{p}=0.7\end{array}$ & $\begin{array}{l}11.2(6.4) \\
\mathrm{p}<0.0001\end{array}$ \\
\hline $\begin{array}{l}\text { Specimen 2, } \\
\text { 1st thawing, 72 h }\end{array}$ & & $\begin{array}{l}11.8(10.2) \\
\mathrm{p}<0.0001\end{array}$ \\
\hline
\end{tabular}

the specimens centrifuged after a storage time of 24 or $72 \mathrm{~h}$ had been put on the turntable 2 and 3 times, respectively, while those centrifuged after 3 and 6 h had only been mixed once. The differences found between mixed and unmixed specimens are shown in figure 3. As the differences were similar under all storage conditions, all specimens were evaluated combined irrespective of where they had been kept prior to centrifugation.

\section{Storage Time and Conditions}

To simplify the evaluation of the impact of storage time and conditions prior to centrifugation on TIMP-1 levels, only the specimens which had not been mixed were considered. It was found that in all these specimens, TIMP-1 levels were higher than in the specimens centrifuged and measured directly after venipuncture. Corresponding data are shown in table 1 and figure 4 . The increase was significant after all tested time intervals of 3, 6, 24 and $72 \mathrm{~h}$, the extent of the increase, however, varied depending on the storage conditions. TIMP1 levels increased significantly more in the specimens stored at $20^{\circ} \mathrm{C}$ than in those stored at $4{ }^{\circ} \mathrm{C}$ and the in- crease was significantly higher in the specimens exposed to light than in the covered ones. Results are shown in figure 4 .

\section{Discussion}

Many results have been published indicating that TIMP-1 may have clinical utility as a biomarker in colorectal cancer [2-6] and in other diseases [7-16]. Several studies have shown that TIMP-1 blood levels are dependent on preanalytical conditions [17-22]. During our own investigations on the clinical use of TIMP-1 we made some unexpected observations that likely could only be explained by a possible bias of different specimen handling used. Since the existing data on this topic could not explain our observations adequately, we performed the present study. In contrast to the results presented by Holten-Andersen et al. [19] and Alby et al. [21], we measured increased TIMP-1 levels after each freezing and thawing cycle, which is in accord with our previous observations [unpubl. data] and which indicates that the increase in 
Fig. 3. Mechanical manipulation: TIMP-1 levels in all mixed specimens compared to those measured in the unmixed specimens after all tested time intervals.

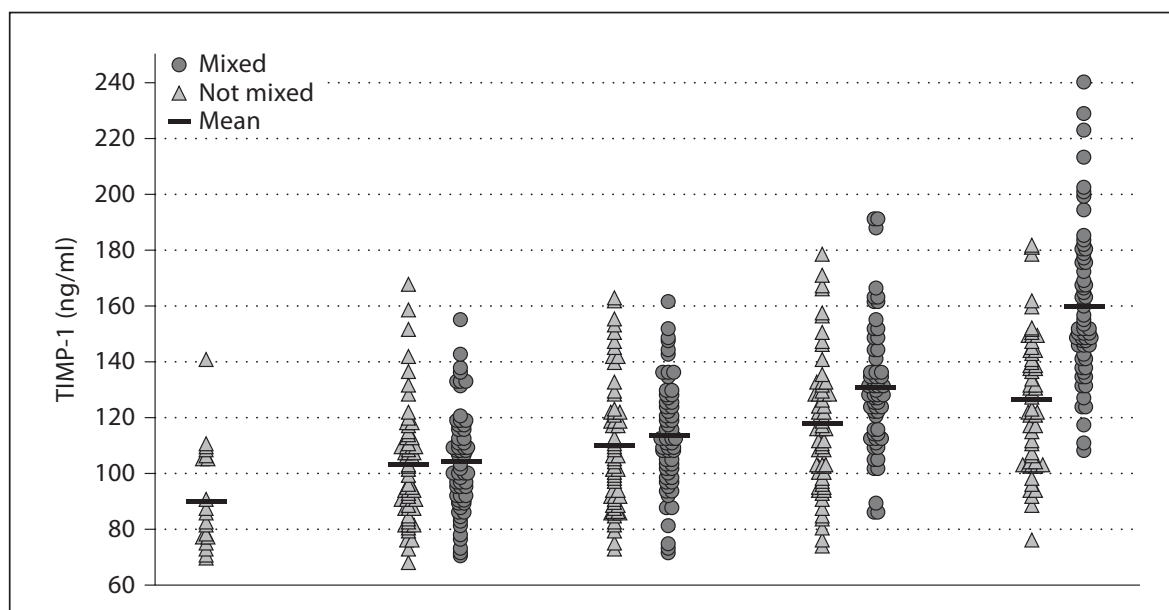

\begin{tabular}{|l|l|l|l|l|}
\hline Difference (mixed - not mixed) & After $3 \mathrm{~h}$ & After $6 \mathrm{~h}$ & After $24 \mathrm{~h}$ & After $72 \mathrm{~h}$ \\
\hline Mean & 0.0 & 1.0 & 8.2 & 27.8 \\
\hline $\mathrm{SD}$ & 11.5 & 11.1 & 10.2 & 19.9 \\
\hline $\mathrm{p}$ value & 0.994 & 0.489 & $<0.001$ & $<0.001$ \\
\hline
\end{tabular}

Table 1. Time to centrifugation

\begin{tabular}{llllr}
\hline & \multicolumn{4}{l}{ Mean difference of TIMP-1 levels to directly measured specimens } \\
\cline { 2 - 5 } & after 3 h & after 6 h & after 24 h & after $72 \mathrm{~h}$ \\
\hline Storage at $20^{\circ} \mathrm{C}$, daylight & $21.0(12.5)$ & $28.0(13.1)$ & $38.5(13.0)$ & $45.9(15.1)$ \\
Storage at $20^{\circ} \mathrm{C}$, covered & $10.0(9.8)$ & $18.7(14.5)$ & $28.7(14.5)$ & $39.1(14.3)$ \\
Storage at $4^{\circ} \mathrm{C}$, daylight & $7.7(6.7)$ & $11.7(13.3)$ & $14.5(13.1)$ & $23.8(12.1)$ \\
\hline
\end{tabular}

Figures in parentheses are SD. The differences found between TIMP-1 values in the specimens stored before centrifugation and those centrifuged directly after blood collection for all time intervals and storage conditions are shown. $\mathrm{p}<0.001$ for all obtained results.

TIMP-1 is not dependent on the storage time at $-80^{\circ} \mathrm{C}$, but is caused by the freezing/thawing procedure itself. While Alby et al. [21] used heparin plasma instead of EDTA plasma and a different centrifugation mode, Holten-Andersen et al. [19] performed their freeze/thaw study similar to our trial. So even if the reason for these different findings cannot be found, it has to be stated that studies on the clinical use of TIMP-1 should only be performed using plasma specimens which are comparable regarding their preanalytical factors, such as storage time and number of previous freeze/thaws. Our results concerning specimen handling prior to centrifugation clearly show that TIMP-1 increases when whole blood speci- mens are stored prior to their further processing into plasma. This phenomenon can possibly be explained by the degradation of platelets in these blood specimens, as platelets contain high concentrations of TIMP-1 as reported by Cooper et al. [23]. While in our trial the observed increase was significant even after a storage time of $3 \mathrm{~h}$, Holten-Andersen et al. [19] only obtained a significant increase after a storage time of $8 \mathrm{~h}$ in their similar trial. We cannot confirm that reliable TIMP-1 values can be measured when blood specimens are centrifuged within $8 \mathrm{~h}$. Our findings rather suggest that the increase is a steady process and that blood specimens have to be centrifuged and measured immediately after venipunc- 
Fig. 4. TIMP-1 levels in dependency of storage time under different storage conditions. Figures are means with SD in parentheses.

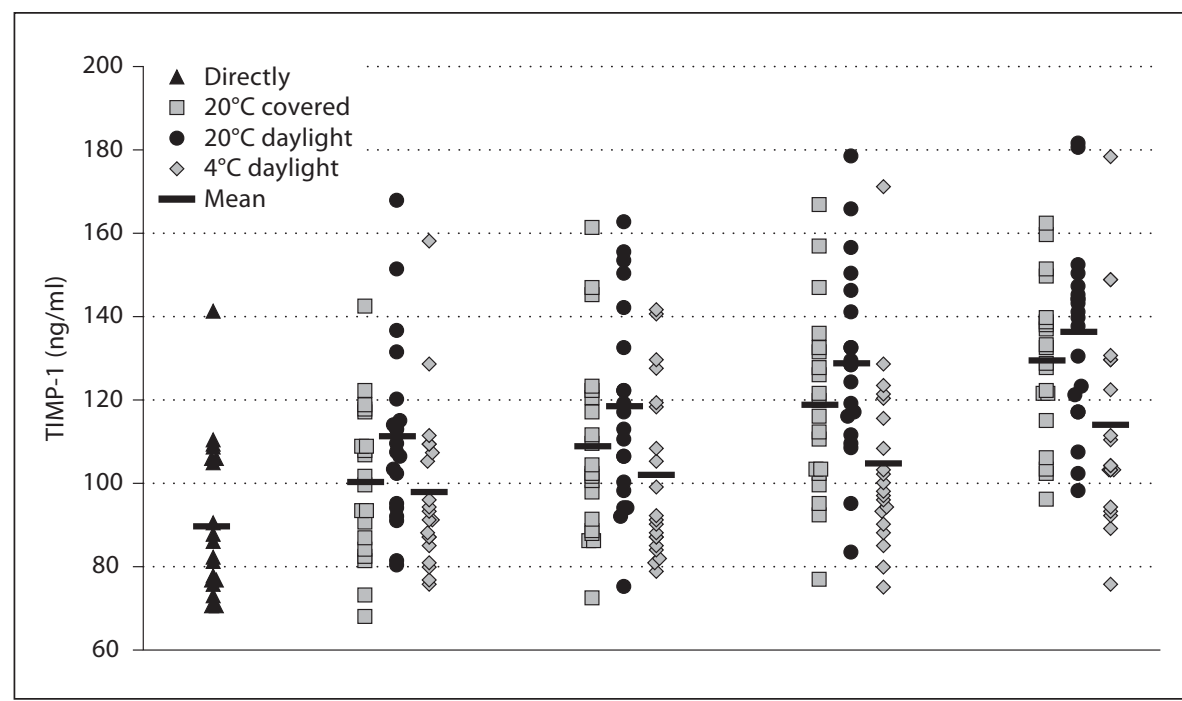

\begin{tabular}{|l|l|l|l|l|}
\hline Difference & After $3 \mathrm{~h}$ & After $6 \mathrm{~h}$ & After $24 \mathrm{~h}$ & After $72 \mathrm{~h}$ \\
\hline Daylight - covered $\left(20^{\circ} \mathrm{C}\right)$ & $11.1(9.3)$ & $9.2(8.7)$ & $9.8(8.9)$ & $6.8(11.4)$ \\
& $\mathrm{p}<0.001$ & $\mathrm{p}<0.001$ & $\mathrm{p}<0.001$ & $\mathrm{p}<0.001$ \\
\hline $20^{\circ} \mathrm{C}-4^{\circ} \mathrm{C}$ (daylight) & $13.3(10.0)$ & $16.3(14.8)$ & $24.0(15.9)$ & $22.1(12.0)$ \\
& $\mathrm{p}<0.001$ & $\mathrm{p}<0.001$ & $\mathrm{p}<0.001$ & $\mathrm{p}<0.001$ \\
\hline
\end{tabular}

ture in order to obtain reliable TIMP-1 values. The lack of significance after $8 \mathrm{~h}$ in the study of Holten-Andersen et al. [19] might be caused by the relatively low number of blood donors: they only used 8 blood donors, while in our trial 20 persons were involved. Furthermore, the automated prototype Architect immunoassay for TIMP-1 used in our trial provides more precise and reliable data than the manual ELISA kits used so far, especially when specimens have to be measured quickly and in several runs per day as necessary for the investigation of preanalytical biases. Additionally, we investigated the impact of storage temperature and exposure to light on TIMP-1 levels. According to the findings of Lomholt et al. [22], storage of the whole blood specimens in the cold storage room at $4{ }^{\circ} \mathrm{C}$ could reduce the increase in TIMP-1. Similarly, covering the testing tubes with aluminum foil to protect them from light had the same effect, even if to a lesser extent. These results lead to the conclusion that blood specimens used for the measurement of TIMP-1 should be kept covered and refrigerated for as short as possible prior to their centrifugation and measurement, which can hardly be realized in daily clinical routine; as TIMP-1 levels had already increased after a storage time of $3 \mathrm{~h}$, which was the shortest time interval tested, no definite recommendation regarding a maximum storage time can be given. We furthermore tested the impact of mechanical manipulation on the whole blood specimens as they might be exposed to when they have to be sent by post to the laboratory. A significant increase in TIMP-1 values could only be found in the specimens mixed twice or more after $24 \mathrm{~h}$ or later with most of them being macroscopically hemolytic. This indicates that any commonly used transportation of the specimens can be performed within $24 \mathrm{~h}$ without causing an increase in TIMP-1. However, considering the fact that TIMP-1 values steadily increase when whole blood is stored prior to centrifugation, it has to be suggested that transportation of specimens should preferably be performed after processing them into plasma and placing them in secondary tubes.

The present study underlines the importance of a careful investigation of the stability of new biomarkers and the need for specimen handling standards in order to obtain reliable data.

\section{Acknowledgement}

The authors thank laboratory technician Cornelia Scheuer for her skillful and reliable laboratory work. 


\section{References}

1 Baker T, Tickle S, Wasan H, Docherty A, Isenberg D, Waxman J: Serum metalloproteinases and their inhibitors: markers for malignant potential. Br J Cancer 1994;70:506512.

2 Holten-Andersen MN, Murphy G, Nielsen HJ, Pedersen AN, Christensen IJ, HoyerHansen G, Brünner N, Stephens RW: Quantitation of TIMP-1 in plasma of healthy blood donors and patients with advanced cancer. Br J Cancer 1999;80:495-503.

3 Holten-Andersen MN, Christensen IJ, Nielsen HJ, Stephens RW, Jensen V, Nielsen $\mathrm{OH}$, Sorensen S, Overgaard J, Lilja H, Harris A, Murphy G, Brünner N: Total levels of tissue inhibitor of metalloproteinases 1 in plasma yield high diagnostic sensitivity and specificity in patients with colon cancer. Clin Cancer Res 2002;8:156-164.

4 Oberg A, Höyhtyä M, Tavelin B, Stenling R, Lindmark G: Limited value of preoperative serum analyses of matrix metalloproteinases (MMP-2, MMP-9) and tissue inhibitors of matrix metalloproteinases (TIMP-1, TIMP2) in colorectal cancer. Anticancer Res 2000; 20:1085-1091.

5 Holten-Andersen MN, Nielsen HJ, Sorensen S, Jensen V, Brünner N, Christensen IJ: Tissue inhibitor of metalloproteinases-1 in the postoperative monitoring of colorectal cancer. Eur J Cancer 2006;42:1889-1896.

6 Sorensen NM, Byström P, Christensen IJ, Berglund A, Nielsen HJ, Brünner N, Glimelius B: TIMP-1 is significantly associated with objective response and survival in metastatic colorectal cancer patients receiving combination of irinotecan, 5-fluorouracil, and folinic acid. Clin Cancer Res 2007;13: 4117-4122.

7 Lipton A, Ali SM, Leitzel K, Demers L, Evans DB, Hamer P, Brown-Shimer S, Pierce K, Carney W: Elevated plasma tissue inhibitor of metalloproteinase-1 level predicts decreased response and survival in metastatic breast cancer. Cancer 2007;109:1933-1939.
8 Derosa G, D’Angelo A, Tinelli C, Devangelio E, Consoli A, Miccoli R, Penno G, Del Prato S, Paniga S, Cicero AF: Evaluation of metalloproteinase 2 and 9 levels and their inhibitors in diabetic and healthy subjects. Diabetes Metab 2007;33:129-134

9 Kralisch S, Bluher M, Tonjes A, Lossner U, Paschke R, Stumvoll M, Fasshauer M: Tissue inhibitor of metalloproteinase-1 predicts adiposity in humans. Eur J Endicrinol 2007; 156:257-261.

10 Glowinska-Oleszewska B, Urban M: Elevated matrix metalloproteinase 9 and tissue inhibitor of metalloproteinase 1 in obese children and adolescents. Metabolism 2007;56: 799-805.

11 Jguirim-Souissi I, Jelassi A, Addad F, Ben Farhat M, Bouslema A, Rouis M, Slimane MN: Plasma metalloproteinase- 12 and tissue inhibitor of metalloproteinase-1 levels and presence, severity, and outcome of coronary artery disease. Am J Cardiol 2007;100:2327.

12 McGavigan AD, Maxwell PR, Dunn FG: Serological evidence of early remodelling in high-risk non-ST elevation acute coronary syndromes. Int J Cardiol 2008;125:22-27.

13 Elmas E, Lang S, Erik Dempfle C, Kälsch T, Hannak D, Sueselbeck T, Wolpert C, Borggrefe $M$, Brueckmann M: High levels of tissue inhibitor of metalloproteinase-1 (TIMP1) and interleukin-8 (IL-8) characterize patients prone to ventricular fibrillation complicating myocardial infarction. Clin Chem Lab Med 2007;45:1360-1365.

14 Giansante C, Fiotti N, Di Chiara A, Altamura N, Wasserman S, Fioretti P, Guarnieri G: In-hospital outcome of patients with acute coronary syndrome: relationship with inflammation and remodelling markers. J Cardiovasc Med (Hagerstown) 2007;8:602-607.

15 Cavusoglu E, Ruwende C, Chopra V, Yanamadala S, Eng C, Clark LT, Pinsky DJ, Marmur JD: Tissue inhibitor of metalloproteinase-1 (TIMP-1) is an independent predictor of all-cause mortality, cardiac mortality, and myocardial infarction. Am Heart J 2006;151: 1101.e1-e8.
16 Hoffmann U, Bertsch T, Dvortsak E, Liebetrau C, Lang S, Liebe V, Huhle G, Borggrefe M, Brueckmann M: Matrix-metalloproteinases and their inhibitors are elevated in severe sepsis: prognostic value of TIMP-1 in severe sepsis. Scand J Infect Dis 2006;38: 867-872.

17 Lein M, Nowak L, Jung K, Koenig F, Lichtinghagen R, Schnorr D, Loening SA: Analytical aspects regarding the measurement of metalloproteinases and their inhibitors in blood. Clin Biochem 1997;30:491-496.

18 Imafuku Y, Meguro S, Kanno K, Hiraki H, Nemoto U, Hata R, Takahashi K, Miura Y, Yoshida $\mathrm{H}$ : The effect of EDTA contaminated in sera on laboratory data. Clin Chim Acta 2002;325:105-111.

19 Holten-Andersen MN, Schrohl AS, Brünner N, Nielsen HJ, Høgdall CK, Høgdall EV: Evaluation of sample handling in relation to levels of tissue inhibitor of metalloproteinases- 1 measured in blood by immunoassay. Int J Biol Markers 2003;18:170-176.

20 Jung K: Preanalytical biases in measurement of matrix metalloproteinases and their inhibitors in peripheral blood. J Rheumatol 2007;34:890-892.

21 Alby C, Ben Abdesselam O, Foglietti MJ, Beaudeux JL: Preanalytical aspects regarding the measurement of metalloproteinase- 9 and tissue inhibitor of metalloproteinase-1 in blood. Clin Chim Acta 2002;325:183186.

22 Lomholt AF, Frederiksen CB, Christensen IJ, Brünner N, Nielsen HJ: Plasma tissue inhibitor of metalloproteinases-1 as a biological marker? Pre-analytical considerations. Clin Chim Acta 2007;380:128-132.

23 Cooper TW, Eisen AZ, Stricklin GP, Welgus HG: Platelet-derived collagenase inhibitor: characterization and subcellular localization. Proc Natl Acad Sci USA 1985;82:27792783 